\title{
ATRIAL FIBRILLATION AS A PREDICTOR OF IN- HOSPITAL MORTALITY IN PATIENTS WITH ISCHEMIC STROKE.
}

\author{
DR. MUHAMMAD BASSIM ARSHAD, MBBS, \\ DEPARTMENT OF MEDICINE, \\ NISHTAR HOSPITAL, MULTAN, PAKISTAN. \\ DR. KHAWAJA MUHAMMAD AFNAN, MBBS, \\ DEPARTMENT OF MEDICINE, \\ NISHTAR HOSPITAL, MULTAN, PAKISTAN. \\ DR. MOIZ HASSAN AZDEE, MBBS, \\ DEPARTMENT OF MEDICINE, \\ NISHTAR HOSPITAL, MULTAN, PAKISTAN.
}

\begin{abstract}
;
Objective; To determine the frequency of in - hospital mortality in atrial fibrillation patients having ischemic stroke at a tertiary care hospital. Study design; Cross-sectional study. Setting; Department of Medicine, Nishtar Hospital, Multan. Material and methods; All the cases of ischemic stroke having atrial fibrillation (171), fulfilling inclusion criteria was recruited from indoor and outdoor of Department of General Medicine, Nishtar Hospital Multan from May 2018 to May 2019. These patients were investigated for the presence of atrial fibrillation, diabetes, hypertension, smoking and obesity and data was analyzed by SPSS version 18. Results; A total of 171 patients with ischemic stroke having atrial fibrillation were taken. Of these 171 patients, 112 $(65.5 \%)$ were male patients while $59(34.5 \%)$ were female patients. Mean age of our patients was $58.32 \pm 12.06$ years, ranging from 41 to 81 years while $54(31.6 \%)$ were aged up to 50 years and $119(69.6 \%)$ were aged more than 50 years. Of these 171 patients, $52(30.4 \%)$ were from rural and $119(69.6 \%)$ from urban areas, $87(50.9 \%)$ belonged to poor families and $84(49.1 \%)$ belonged to middle income families. Sixty-six $(38.6 \%)$ were diabetic and $106(62 \%)$ were hypertensive. Mean body mass index was $25.39 \pm 3.81 \mathrm{~kg} / \mathrm{m}^{2}$ with obesity was present in 46 $(26.9 \%)$ while $66(38.6 \%)$ were smokers and all smokers were male patients. Mortality was noted in $72(42.1 \%)$ in ischemic stroke patients having atrial fibrillation. Conclusion; Frequency of mortality was high in our study among patients with ischemic stroke having atrial fibrillation. Mortality was significantly associated with male gender, smoking. diabetes, hypertension and obesity.
\end{abstract}

Keywords; Ischemic stroke, atrial fibrillation, risk factors.

DOI: $10.7176 / \mathrm{JMPB} / 55-06$

Publication date:May $31^{\text {st }} 2019$

\section{Introduction;}

Stroke, having 2 major subtypes; Ischemic stroke and hemorrhagic stroke, is $2^{\text {nd }}$ leading cause of deaths worldwide ${ }^{1,2}$. It may be associated with more than 6 million deaths each year, of which $66 \%$ deaths occur in resource limited countries. Treatment strategies for ischemic and hemorrhagic strokes vary greatly as ischemic stroke treatment involves thrombolytic and antiplatelet therapies whereas hemorrhagic stroke management involves hemostatic therapeutic option to improve clinical outcomes. It is not associated with increased rates of mortality but it is also associated with significant increase in adulthood physical disability and mental health impairment. Functional disability in these patients further complicates its prognosis being more prevalent in resource limited nation, moreover such patients of such countries are almost 10 years younger than that of western population ${ }^{3,4}$. WHO estimates that till 2020 stroke will remain $2^{\text {nd }}$ leading cause of death in developed as well as developing countries after ischemic heart disease (IHD) ${ }^{3}$.

An obstruction of a blood vessel which supplies blood to the brain tissue leads to the development of typical sign and symptoms of ischemic stroke that comprises approximately $90 \%$ of total stroke patients in our patients. Stroke risk factors are categorized as non-modifiable factors "age, family history, prior stroke, gender and 
ethnicity" and modifiable risk factors such as "hypertension, diabetes mellitus, coronary artery disease, arterial fibrillation, dyslipidemia, smoking, obesity, alcohol abuse and physical inactivity" ${ }^{5-7}$.

Atrial fibrillation (AF) is an important modifiable risk factor of ischemic stroke which increases $4-5$ folds of its risk in these patients. ${ }^{8}$ Different underlying factors of stroke for atrial fibrillation increase with advancing age from $1.5 \%$ among patients aged 50 to 59 years to approximately $25 \%$ among person aged more than 80 years. The risk of stroke and AF both increase with age, it is anticipated that there was greater numbers of patients presenting with an acute stroke and concomitant $\mathrm{AF}$ as the population ages ${ }^{9}$. Atrial fibrillation is also associated with high in-hospital mortality in patients with Ischemic stroke ${ }^{10}$. Atrial fibrillation leads to adverse clinical outcome in patients having ischemic stroke. Recent studies have also documented atrial fibrillation to be an independent predictor of mortality in patients with ischemic stroke ${ }^{11,12}$.

\section{Material and Methods;}

All the cases of ischemic stroke having atrial fibrillation (171), fulfilling inclusion criteria was recruited from indoor and outdoor of Department of General Medicine, Nishtar Hospital Multan from May 2018 to May 2019. Patients with hemorrhagic stroke (on CT scan), known patients with coronary artery disease and heart failure and diagnosed cases of brain tumors were excluded. Atrial Fibrillation was defined by "presence of any of a group of conditions in which the electrical activity of the heart was irregularly irregular detected on electrocardiogram by absence of $\mathrm{p}$ waves and irregular heart rhythm (irregular R-R interval) as assessed on ECG" and Ischemic Stroke was defined as CT scan brain plan shows hypo dense area in specific vascular territory. Once registered in the study, routine investigations were done including chest X-Ray, ECG and Echocardiography. Data was entered and analyzed by computer program SPSS-18. Descriptive statistics was applied to calculate mean and standard deviation for the age of patients. Frequencies and percentages was calculated for categorical variables like mortality (Yes/No), age groups, gender, history of hypertension, diabetes, residential status, family history of stroke, smoking and alcohol consumption. Effect modifiers like age, gender, hypertension, residential status, diabetes, Obesity and smoking were controlled by stratification and P-value equal or less than 0.05 was considered as significant.

\section{Results;}

A total of 171 patients with ischemic stroke having atrial fibrillation were taken. Of these 171 patients, 112 $(65.5 \%)$ were male patients while $59(34.5 \%)$ were female patients. Mean age of our patients was $58.32 \pm 12.06$ years, ranging from 41 to 81 years while $54(31.6 \%)$ were aged up to 50 years and $119(69.6 \%)$ were aged more than 50 years. Of these 171 patients, $52(30.4 \%)$ were from rural and $119(69.6 \%)$ from urban areas, $87(50.9 \%)$ belonged to poor families and $84(49.1 \%)$ belonged to middle income families. Sixty-six $(38.6 \%)$ were diabetic and $106(62 \%)$ were hypertensive. Mean body mass index was $25.39 \pm 3.81 \mathrm{~kg} / \mathrm{m}^{2}$ with obesity was present in 46 $(26.9 \%)$ while $66(38.6 \%)$ were smokers and all smokers were male patients. Mortality was noted in $72(42.1 \%)$ in ischemic stroke with atrial fibrillation.

\section{Discussion;}

Ischemic stroke is associated with significant increase in morbidity, mortality and functional disabilities among survivors which has an impact on their quality of life, extra economical burden and increased healthcare costs for patients and hospital authorities. A total of 171 patients with ischemic stroke having atrial fibrillation were taken. Of these 171 patients, $112(65.5 \%)$ were male patients while 59 (34.5\%) were female patients. A study conducted by Buchwald et al ${ }^{13}$ from Sweden has also reported $52 \%$ male patients predominance. However Friberg et al ${ }^{14}$ reported female gender predominance, contrary to our findings. A study done by Saposnik et al ${ }^{15}$ from Canada also documented $53 \%$ male patients with ischemic stroke. Khan et al ${ }^{16}$ from Quetta also reported $65 \%$ male patients with ischemic stroke, similar to our findings. Shaikh et al ${ }^{17}$ also reported $61 \%$ male patients having ischemic stroke, similar to our results.

Mean age of our patients was $58.32 \pm 12.06$ years, ranging from 41 to 81 years while $54(31.6 \%)$ were aged up to 50 years and $119(69.6 \%)$ were aged more than 50 years.

A study conducted by Buchwald et al ${ }^{13}$ from Sweden has also reported $73.1 \pm 12.3$ years mean age which shows occurrence of the stroke in our population is almost 15 years earlier than that of Swedish population. Thus ischemic stroke in our population has economical impacts on the national economy as it affects predominantly main workforce of our society leaving them permanently disable. Khan et al ${ }^{16}$ from Quetta also reported $59.17 \pm$ 10.52 years mean age of ischemic stroke patients, similar to our results. Shaikh et al ${ }^{17}$ also reported similar results comparable to our findings. 
Of these 171 patients, $52(30.4 \%)$ were from rural and $119(69.6 \%)$ from urban areas, $87(50.9 \%)$ belonged to poor families and $84(49.1 \%)$ belonged to middle income families. Sixty-six (38.6\%) were diabetic and 106 $(62 \%)$ were hypertensive. A study conducted by Buchwald et al ${ }^{13}$ from Sweden has also reported diabetes in $21.2 \%$ patients with ischemic stroke similarly hypertension was present in $62.8 \%$ patients, being close to our findings. Friber et al ${ }^{14}$ also documented $22.5 \%$ diabetes and $72 \%$ hypertension in ischemic stroke with atrial fibrillation. A study done by Saposnik et al ${ }^{15}$ from Canada also documented $25.5 \%$ diabetes and $68.1 \%$ hypertension which is similar to our findings. . Khan et al ${ }^{16}$ from Quetta also reported similar results. Shaikh et al ${ }^{17}$ also reported $32.7 \%$ diabetes and $60.6 \%$ hypertension in ischemic stroke, close to our findings.

Mean body mass index was $25.39 \pm 3.81 \mathrm{~kg} / \mathrm{m}^{2}$ with obesity was present in $46(26.9 \%)$ while $66(38.6 \%)$ were smokers and all smokers were male patients. A study conducted by Buchwald et al ${ }^{13}$ from Sweden has reported smoking in $14.2 \%$ patients which is quite lower than those of our patients. Similarly another study by Friberg et al ${ }^{14}$ also reported very low smoking rates compared with our trends. This high trend in smoking among our patients can be avoided by proper implementation of local legislation to control this practice which is also major cause of development of IHD and cancers as well.

Atrial fibrillation in stroke patients is associated with adverse clinical outcomes ${ }^{11,12}$. Mortality was noted in 72 $(42.1 \%)$ in ischemic stroke patients having atrial fibrillation. Our study results are in compliance with Buchwald et al ${ }^{13}$ from Sweden and Saposnik et al ${ }^{15}$ from Canada.

\section{Conclusion;}

Frequency of in - hospital mortality was high in our study among patients with ischemic stroke having atrial fibrillation. Mortality was significantly associated with male gender, smoking. diabetes, hypertension and obesity.

\section{References;}

1. Mwita CC, Kajia D, Gwer S, Etyang A, Newton CR. Accuracy of clinical stroke scores for distinguishing stroke subtypes in resource poor settings: A systematic review of diagnostic test accuracy. J Neurosci Rural Pract. 2014;5(4):330-9.

2. Khan NI, Naz L, Mushtaq S, Rukh L, Ali S, Hussain Z. Ishemic stroke: Prevalence of modifiable risk factors in male and female patients in Pakistan. Pak J Pharm Sci 2009;22(1):62-7.

3. Khan SF, Zafar A, Malik A. Stroke in Pakistan: reality, challenges and a call for action. Pak J Neurol Sci. 2008;3:14-9.

4. Feigin VL. Stroke in developing countries: can the epidemic be stopped and outcomes improved? Lancet Neurol 2007;6(2):94-7.

5. Okokhere PO, Bankole IA, Erohubie CA. Characteristics, risk factors, and case fatality rate of stroke in hospitalized patients in semi-urban South Nigeria. SAGE Open Medicine 2013; doi:10.1177/2050312113516112.

6. Zahra F, Kidwai SS, Siddiqi SA, Khan RM. Frequency of newly diagnosed diabetes mellitus in acute ischaemic stroke patients. J Coll Physician Surg Pak. 2012;22(4):226-9.

7. Abid N, Khan SA, Taseer IH. Frequency of Hyperlipidemia in Patients Presenting with Ischemic Stroke. Pak J Med Health Sci. 2012;6(2):423-7.

8. Goldstein LB, Bushnell CD, Adams RJ, Appel LJ, Braun LT, Chaturvedi S, et al. Guidelines for the primary prevention of stroke: a guideline for healthcare professionals from the American Heart Association/American Stroke Association. Stroke . 2011;42:517-84

9. Saposnik G, Gladstone D, Raptis R, Zhou L, Hart RG; Investigators of the Registry of the Canadian Stroke Network (RCSN) and the Stroke Outcomes Research Canada (SORCan) Working Group. Atrial fibrillation in ischemic stroke: predicting response to thrombolysis and clinical outcomes. Stroke. 2013 Jan;44(1):99-104.

10. Ong CT, Wong YS, Wu CS, Su YH. Atrial fibrillation is a predictor of in-hospital mortality in ischemic stroke patients. Ther Clin Risk Manag. 2016 Jun 29;12:1057-64.

11. Lou YP, Yan SQ, Zhang S, Chen ZC, Wan JP, Lou M. Impact of atrial fibrillation on clinical outcome in patients with acute ischemic stroke undergoing thrombolytic therapy. Zhejiang Da Xue Xue Bao Yi Xue Ban. 2014 Jan;43(1):28-35. 
12. Li S, Wang S, Gu M, Cao B. Characteristics and outcome of acute ischemic stroke patients with atrial fibrillation. Zhonghua Yi Xue Za Zhi. 2015 Nov 17;95(43):3509-13.

13. Buchwald F, Norrving B, Petersson J.Atrial Fibrillation in Transient Ischemic Attack Versus Ischemic Stroke: A Swedish Stroke Register (Riksstroke) Study. Stroke. 2016;47(10):2456-2461.

14. Friberg L, Rosenqvist M, Lindgren A, Terént A, Norrving B, Asplund K. High prevalence of atrial fibrillation among patients with ischemic stroke. Stroke. 2014 Sep;45(9):2599-2605. doi: 10.1161/STROKEAHA.114.006070.

15. Saposnik G, Gladstone D, Raptis R, Zhou L, Hart RG. Atrial fibrillation in ischemic stroke: predicting response to thrombolysis and clinical outcomes. Stroke. 2013 Jan;44(1):99-104.

16. Khan A, Chiragh S, Irfan M, Sherin A. Frequency of seizures and epilepsy after ischaemic stroke J Postgrad Med Inst. 2008;22(2):124-9.

17. Shaikh NA, Bhatty S, Irfan M, Khatri G, Vaswani AS, Jakhrani N. Frequency, characteristics and risk factors of carotid artery stenosis in ischaemic stroke patients. J Pak Med Assoc. 2010;60(1):8-12. 